\title{
Removal of an impaled knife under thoracoscopic guidance
}

\author{
Seth Isenburg $\mathrm{MD}^{1}$, Nicole Jackson $\mathrm{BSc}^{2}$, Riyad Karmy-Jones $\mathrm{MD}^{1,2}$
}

\begin{abstract}
S Isenburg, N Jackson, R Karmy-Jones. Removal of an impaled knife under thoracoscopic guidance. Can Respir J 2008;15(1):39-40.
\end{abstract}

Thoracoscopy is being increasingly utilized in stable patients to manage both blunt and penetrating injuries. The case of a patient who presented with a knife impaled in the chest is reported. The knife was able to be removed under thoracoscopic guidance, avoiding thoracotomy.

Key Words: Impalement; Pleuroscopy; Thoracoscopy

$\mathrm{T}$ horacoscopy has been used acutely and in the subacute setting to both diagnose and manage thoracic injuries and their complications (1). The primary advantage is that by avoiding thoracotomy, postprocedure pain and resulting morbidity may be prevented $(2,3)$. Traditionally, objects impaled in the chest are stabilized until they can be pulled in the operating room under direct visualization. We present a case that illustrates the principles of airway management, patient positioning and the potential role of thoracoscopy.

\section{CASE PRESENTATION}

A 37-year-old woman presented 20 min after being stabbed in the left posterior chest with a long-bladed knife. The entrance was at the level of the fifth intercostal space in the posterior midclavicular line. The knife was still in situ and had been stabilized by the paramedics who had been called to the scene. She was transported with her left side down. On arrival, she had stable vital signs and no gross respiratory distress, and she was taken immediately to the shock/trauma operating suite, where chest radiographs were performed (Figure 1). There was minimal bleeding and air leak from the wound, although the patient had a small amount of subcutaneous emphysema. The decision was made immediately to remove the knife under thoracoscopic guidance, while being prepared to perform thoracotomy. Because of the absence of any respiratory distress, a chest tube was not placed; it was believed that this would delay intubation, add pain, complicate repositioning, and not add to the proposed immediate thoracoscopic evacuation of any hemo- and/or pneumothorax. The patient was intubated with a single-lumen endotracheal tube while still lying on her left side, and was turned sequentially onto her stomach and then onto her right side. The patient was ready for operation within $15 \mathrm{~min}$ of arrival. Thoracoscopy was performed using two ports and a $10 \mathrm{~mm}$, $30^{\circ}$ camera, assisted by placement of a left-sided bronchial

\section{Retrait d'un couteau sous thoracoscopie}

La thoracoscopie est de plus en plus utilisée chez les patients stables, tant pour les traumatismes fermés que pour les traumatismes ouverts. On décrit ici le cas d'une patiente qui a été poignardée et qui a été amenée alors que le couteau se trouvait toujours dans la plaie. Le couteau a pu être retiré sous thoracoscopie, ce qui a permis d'éviter la thoracotomie.

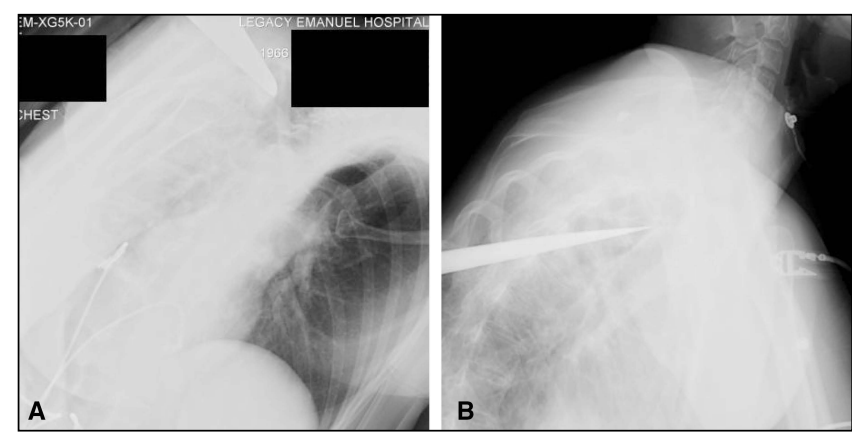

Figure 1) A Cross-table chest radiograph with the patient lying on her left side. The position of the knife suggested that the subclavian artery or proximal descending thoracic aorta might have been at risk. B Lateral chest radiograph, taken from above, with the patient lying on her left side. The path of the knife was cephalad and anterior, which implied that, assuming this was the path taken during the initial assault, the proximal descending aorta was uninjured. However, there still remained the possibility that a subclavian artery or vein may have been injured

blocker. The visualization was made somewhat difficult by the lung not totally deflating, but it was clear that no major vascular structures had been injured and the pericardium was clear. The video thoracoscopy was replaced by a mediastinoscope, and pleuroscopy was completed. The tip of the knife was in the superior segment of the left lower lobe, there was no bleeding from the aorta or chest wall, and the esophagus and pericardium had not been violated. The knife was removed under visualization, and the lung expanded well, with minimal air leak, which was controlled with biological glue. A residual hemothorax of $400 \mathrm{~mL}$ to $500 \mathrm{~mL}$ was evacuated. The patient's chest tube was removed on postoperative day 2 , and she was discharged the following day.

${ }^{1}$ Trauma/Intensive Care Unit, Emanuel Hospital, Portland, Oregon; ${ }^{2}$ Division of Thoracic and Vascular Surgery, Southwest Washington Medical Center, Vancouver, Washington, USA

Correspondence: Dr Riyad Karmy-Jones, Suite 300, Physician's Pavillion, 400 Mother Joseph Place, Vancouver, Washington 98664, USA.

Telephone 360-514-1854, e-mail Karmy@u.washington.edu 


\section{DISCUSSION}

Thoracoscopy is being increasingly utilized for advanced thoracic procedures, including lung resection, with some centres reporting dramatic reductions in morbidity and lengths of hospital stay compared with formal thoracotomy (4). Thoracoscopy has been utilized in the trauma setting both diagnostically and therapeutically $(1-3,5,6)$. It has been argued that thoracoscopy is associated with reduced morbidity and, in selected patients, with a reduction in nontherapeutic thoracotomy $(2,3)$. Thoracoscopy for removal of intrathoracic foreign bodies has been relatively well documented (7-9). However, there are few reports of thoracoscopy being used as an adjunct for managing thoracic impalement injuries when the object is still in situ (10).

Video thoracoscopy offers the advantage of a panoramic view, as well as the ability to repair or treat lung and diaphragmatic injuries. Both the $0^{\circ}$ and $30^{\circ}$ cameras are useful, with the latter permitting easier visualization of the posteromedial mediastinal structures. Pleuroscopy with a mediastinoscope ('rigid' thoracoscopy) permits drainage of hemothorax and pleural exploration without the need for lung isolation (11). At times, such as in the present case, they can be complementary. Some centres argue that if thoracoscopy can be performed with minimal delay, there is no need for tube thoracostomy, which may simply further delay intervention, as well as increase associated pain and morbidity (1). There are, however, a number of critical requirements: the first is that the patient be stable (12), and the second is that there be minimal delay to operation. If there is any doubt as to respiratory or hemodynamic stability, tube thoracostomy must immediately be performed.

The standard, accepted approach to managing a patient with an impalement injury - in whom the foreign object remains in situ - is to stabilize the object until it can be removed under circumstances in which any vascular injury can be controlled. It is believed that the object may tamponade any bleeding. This also makes following the tract of the injury easier to discern. Whether this applies to knives has not been proven, but this has still become the standard of care. Practically, spreading the ribs often results in the impaled object being dislodged or put under tension. When a patient presents with an impaled object in the posterior chest near the midline, structures at risk (other than the lung) on the right side include the diaphragm, liver and heart; on the left, they include the diaphragm, spleen, viscera, heart, aorta and/or esophagus, among others. Airway management can be difficult. Options include intubation with the patient lying on his or her side (as in the present case) or supine between two stretchers. Once intubated, lung isolation can be achieved using an endobronchial blocker system that does not require reintubation.

Thoracoscopy appears to be a useful alternative to thoracotomy in the removal of impaled foreign objects $(9,10)$. It avoids thoracotomy, and the knife (in this case) is not disturbed by the rib retraction required to perform thoracotomy.

\section{CONCLUSIONS}

In patients who present with impalement injuries and who are stable, thoracoscopy allows removal under direct visualization in a rapid and safe manner. This avoids added morbidity and hastens recovery. Key requirements include patient stability, rapid access to the operating suite, the ability to intubate in an awkward position, and experience with both video thoracoscopic and rigid pleuroscopic techniques.

\section{REFERENCES}

1. Divisi D, Battaglia C, De Berardis B, et al. Video-assisted thoracoscopy in thoracic injury: Early or delayed indication? Acta Biomed Ateneo Parmense 2004;75:158-63.

2. Carrillo EH, Richardson JD. Thoracoscopy for the acutely injured patient. Am J Surg 2005;190:234-8.

3. Zhestkov KG, Guliaev AA, Abakumov MM, Voskresenskii OV, Barskii BV. [Thoracoscopy in surgery of thoracic wounds.] Khirurgiia (Mosk) 2003:19-23.

4. McKenna RJ Jr, Houck W, Fuller CB. Video-assisted thoracic surgery lobectomy: Experience with 1100 cases. Ann Thorac Surg 2006;81:421-5.

5. DuBose RA, Karmy-Jones R. Delayed diagnosis and management of an "occult" stab wound to the heart. Am Surg 2005;71:879-81.

6. Nagahiro I, Kaneko A, Taniguchi N, Nakashima A, Nabeyama A. Penetrating chest trauma in which thoracoscopy was helpful; Report of a case. Kyobu Geka 2005;58:248-50.

7. Liu YH, Liu HP, Lin PJ, Chang CH. Thoracoscopic retrieval of foreign body after penetrating chest injury: Report of two cases. Changgeng Yi Xue Za Zhi 1999;22:117-22.

8. Boulanger B, Lahmann B, Ochoa J. Minimally invasive retrieval of a foreign body after penetrating lung injury. Surg Endosc 2001;15:1043.

9. Williams CG, Haut ER, Ouyang H, et al. Video-assisted thoracic surgery removal of foreign bodies after penetrating chest trauma. J Am Coll Surg 2006;202:848-52.

10. Burack JH, Amulraj EA, O’Neill P, Brevetti G, Lowery RC. Thoracoscopic removal of a knife impaled in the chest. J Thorac Cardiovasc Surg 2005;130:1213-4.

11. Karmy-Jones R, Vallieres E, Kralovich K, et al. A comparison of rigid $-\mathrm{v}$ - video thoracoscopy in the management of chest trauma. Injury 1998;29:655-9.

12. Hanvesakul R, Momin A, Gee MJ, Marrinan MT. A role for video assisted thoracoscopy in stable penetrating chest trauma. Emerg Med J 2005;22:386-7. 


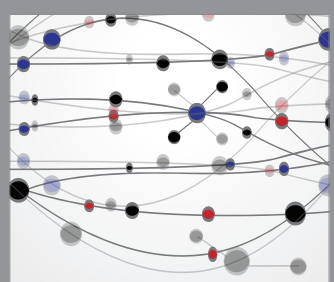

The Scientific World Journal
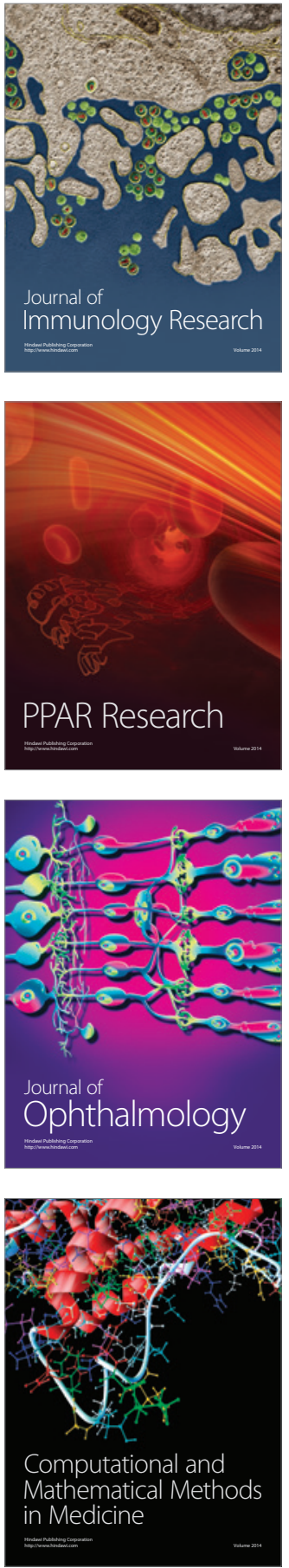

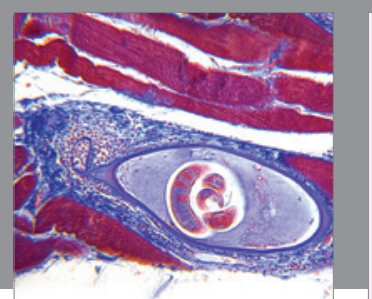

Gastroenterology Research and Practice

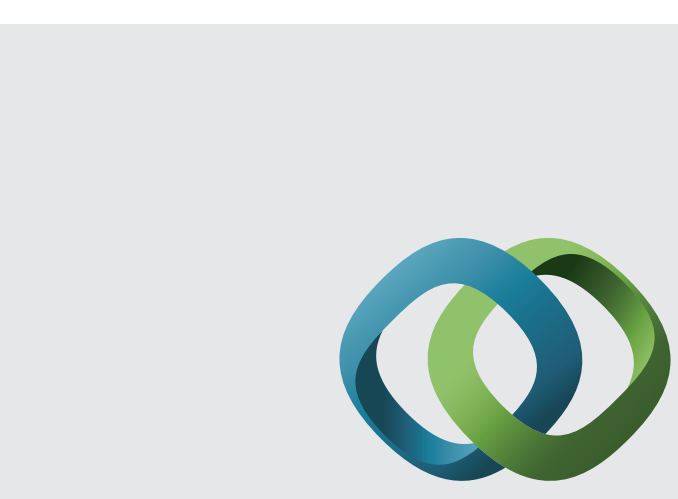

\section{Hindawi}

Submit your manuscripts at

http://www.hindawi.com
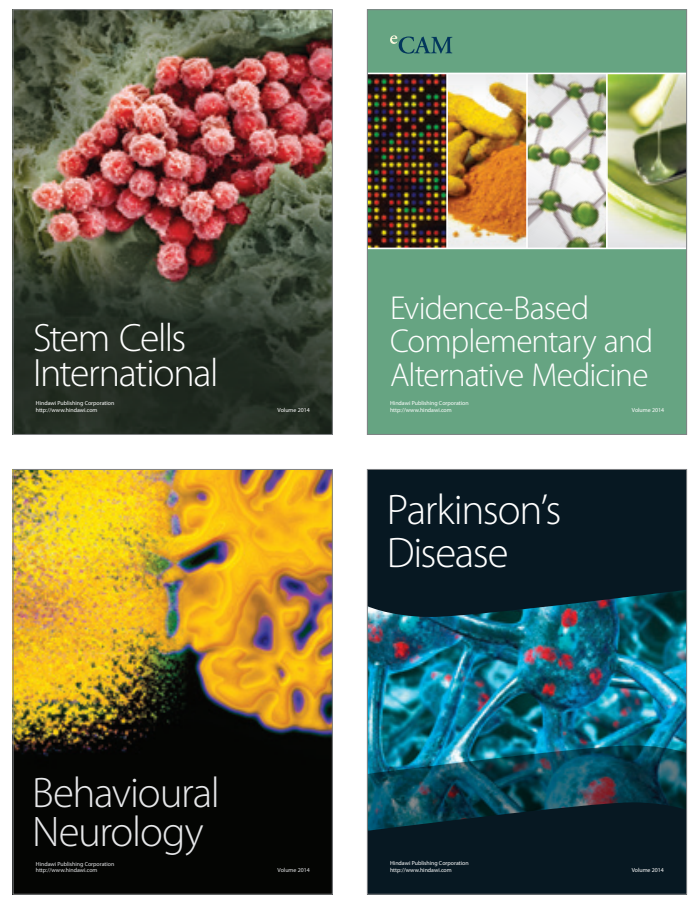
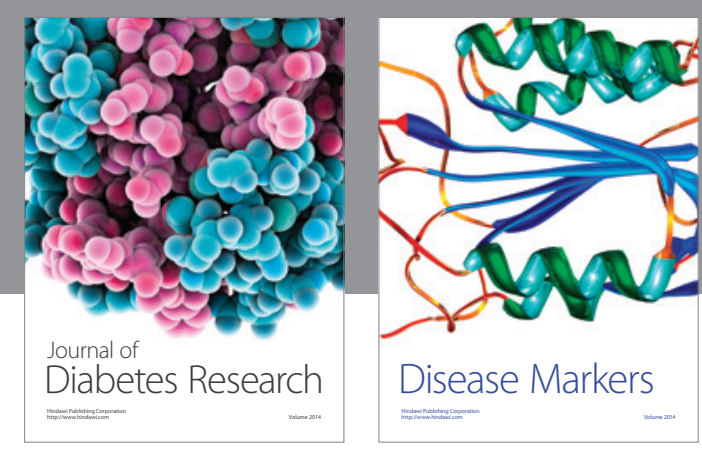

Disease Markers
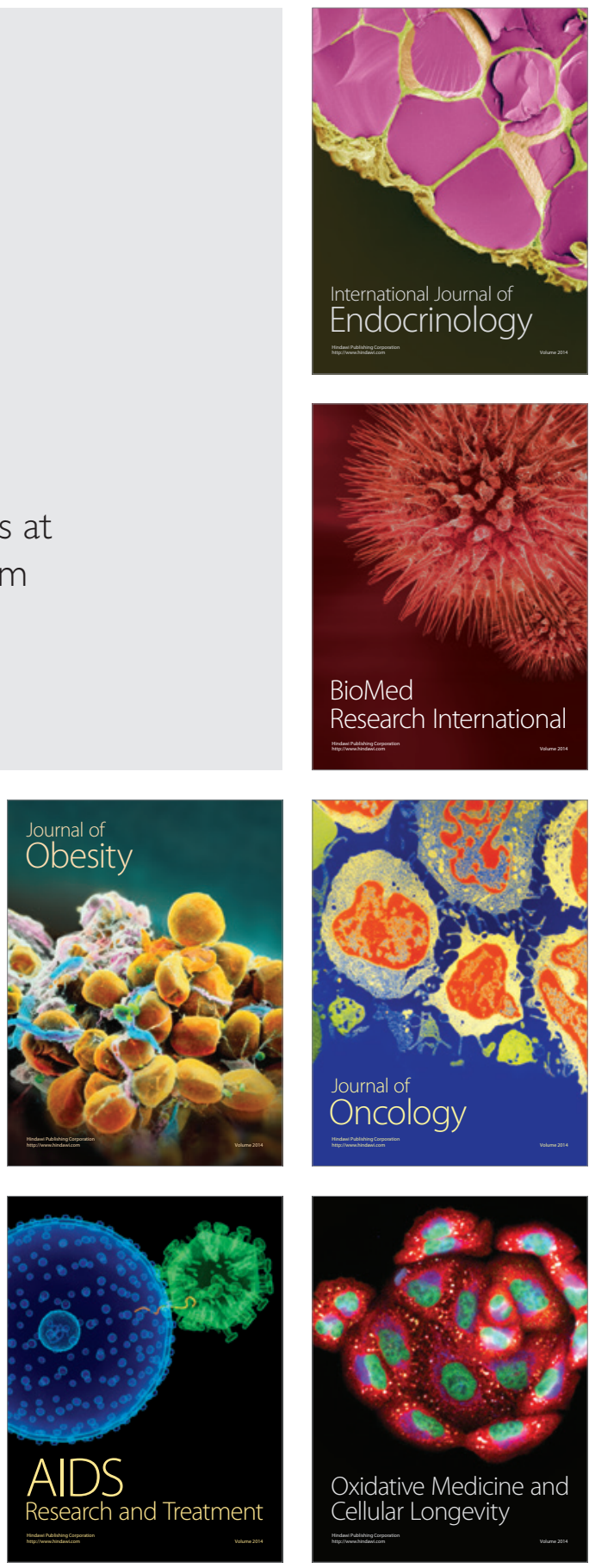